\title{
Score of Fine Motor Skill in Children with Down Syndrome using Nintendo Wii
}

\author{
Puspasari, ${ }^{1}$ Marietta Shanti Prananta, ${ }^{2}$ Eddy Fadlyana ${ }^{3}$ \\ ${ }^{1}$ Faculty of Medicine Universitas Padjadjaran, ${ }^{2}$ Department of Physical Medicine and \\ Rehabilitation Faculty of Medicine Universitas Padjadjaran/Dr. Hasan Sadikin General Hospital \\ Bandung, ${ }^{3}$ Department of Child Health Faculty of Medicine, Universitas Padjadjaran/Dr. Hasan \\ Sadikin General Hospital Bandung
}

\begin{abstract}
Background: Down syndrome occurs due to an extra chromosome 21, known as Trisomy 21 . In addition to delayed cognitive and speech development, children with Down syndrome may also experience delayed gross and fine motor development. Virtual Reality Therapy, such as Nintendo Wii is a computer-based technology that allows users to interact with a virtual three-dimensional scenario and the most innovative physical rehabilitation method. High scores indicate that the player has a good motor skill. This study aimed to examine the difference between the score of fine motor skill in children with and without Down syndrome. Methods: An analytic cross-sectional study was conducted from August to November 2015 to 40 children aged between 9-12 years old who came from public primary schools and special needs schools in Bandung, West Java. They were divided into 2 groups using random gender and age pairing; one group was children with Down syndrome and another other group was normal children. The children' scores of Nintendo Wii game were collected three times. The collected data were statistically analyzed by Chi-Square test.

Results: The proportion of children with low-grade fine motor skill in Down syndrome group was larger than those with high-grade fine motor skill. In the other hand, in normal children group, the proportion was reversed compared to Down syndrome group. There was a significant difference in score of fine motor skill between children with Down syndrome and normal children $(\mathrm{p}=0.000)$.

Conclusions: The fine motor skill of children with Down syndrome is poorer than normal children's. [AM].2016;3(3):371-5]
\end{abstract}

Keywords: Down syndrome, fine motor skill, Nintendo Wii

\section{Introduction}

Down syndrome is a genetic condition which can cause delayed cognitive and motor development as well as physical impairments. ${ }^{1}$ Down syndrome occurs due to the presence of an extra chromosome 21, a condition also known as Trisomy 21. ${ }^{1}$ Children with Down syndrome are subject to varying degree of cognitive developmental delay: mild (IQ 5070), moderate (IQ 35-50), and severe (IQ 20$35){ }^{2}$ Bruni $^{3}$ stated that the cognitive level of a child will influence his motor skills.

Children with low cognitive skills have a high probability to experience a delay in achieving certain motor skills. ${ }^{3}$ Santos et al. ${ }^{4}$ pointed out that fine motor skill is one of the most affected aspects in children with Down syndrome, and impairment of speech skills as well.

Virtual Reality Therapy (VRT) is one of the latest and most innovative physical rehabilitation methods. ${ }^{5}$ This therapy method is a computer-based technology that allows users to interact with a virtual threedimensional scenario. ${ }^{5}$ The therapy method that is able to provide a real simulation during practice can be easily adjusted to the need of patient, can be done repetitively, increase patient motivation in doing practice, and can be done at home. It can also be used to monitor and evaluate the treatment. ${ }^{6}$ OrtizCatalan et al. ${ }^{6}$ stated that the advantage of this therapy focuses on some important aspects to repair the defective motor skill. This defect repair requires the presence of a functional movement in relevant particular

Correspondence: Puspasari, Faculty of Medicine, Universitas Padjadjaran, Jalan Raya Bandung-Sumedang Km.21, Jatinangor, Sumedang, Indonesia, Phone: +62 85722652965 Email: puspass11@gmail.com 
environmental simulation with high intensity repetition in great numbers, and informative feedback response. Thus, VRT can be concluded as a therapy for motor skills that provide all the necessary components, such as necessary therapeutic environment and an interesting and relevant practice that can be adapted to the patient's needs.

Nintendo Wii, one of modern examples of Virtual Reality for gaming, is an interactive virtual game console which is proven effective as a tool for motor skill therapy. ${ }^{5-8}$ In addition to improve motor skill, Nintendo Wii can also be used to measure the degree of motor skill via informative feedback response ${ }^{6}$, based on the score gained after a game is over. High scores indicate that the player has a good motor skill. Based on the description above, the objective of the study was to analyze the difference between the fine motor skill in children with and without Down syndrome by using in-game scores of Nintendo Wii virtual game.

\section{Methods}

An analytic cross-sectional study was conducted from August to November 2015 by collecting Nintendo Wii in-game scores as a measure of fine motor skill from all children with Down syndrome in Special Needs School (Sekolah Luar Biasa, SLB) C Budi Daya, SLB ABCD Caringin, SLB C Cipaganti, and SLB C Sumbersari Antapani Kota Bandung and all normal children in Public Primary School (Sekolah Dasar Negeri, SDN) Babakan Ciparay 4 Kota Bandung West Java. Total sampling was used in the population mentioned above with random gender and age pairing in the members of the two groups. The minimum sample size was determined by performing a pilot study on 20 normal children in SDN Babakan Ciparay to measure the proportion in the normal children group (p1). The minimum sample size which consisted of 20 children for each group was calculated by using the formula for unpaired categorical variables.

The study subjects were selected based on inclusion and exclusion criteria which were confirmed via interview with their caretakers. The inclusion criteria were normal children and children with Down syndrome aged 9 to 12 whose minimal exposure to Nintendo Wii were less than 4 hours a month. The exclusion criteria in this study were orthopedic limitations in performing exercises, such as deformities in neck, shoulder, arm, and wrist; and positive history of seizures. Selected subjects were given explanation in the study procedures. The subjects and their caretakers were given a chance to ask questions about the procedures. The caretakers and the subjects who agreed to participate in a signed informed consent form were included in this study. The subjects from the two children groups were matched based on their age and gender. The overall sizes of the two groups were also matched.

Fine motor skill was measured by collecting in-game scores in the virtual game Cooking Mama (C), a part of Nintendo Wii. This cooking simulation game making the player simulate cutting, dicing, peeling, and mixing move was selected with the consideration that this study aimed to examine fine motor skill. Such movements require precise upper extremities coordination depending on fine motor skill. Before each measurement, each subject was introduced to the method of using Nintendo Wii for two 10-minute sessions by the operator. All subjects were to finish three game sessions whose scores would be averaged and then collected as data. The scores were further categorized into two categories: $0-50$ and 51100 . The score categories were interpreted as low fine motor skill and high fine motor skill respectively. The collected data were analyzed statistically by Chi-Square test.

The purpose and the methods adopted by

Table 1 Gender and Age Distribution of the Children $(n=40)$

\begin{tabular}{|c|c|c|c|c|c|c|c|}
\hline & & \multirow{2}{*}{ Gender } & \multicolumn{4}{|c|}{ Age (years) } & \multirow{2}{*}{ Total } \\
\hline & & & 9 & 10 & 11 & 12 & \\
\hline \multirow{5}{*}{$\begin{array}{l}\text { Children } \\
\text { Group }\end{array}$} & \multirow{2}{*}{$\begin{array}{c}\text { Down } \\
\text { syndrome }\end{array}$} & Male & 2 & 3 & 4 & 1 & 10 \\
\hline & & Female & 2 & 4 & 2 & 2 & 10 \\
\hline & \multirow{3}{*}{ Normal } & Male & 2 & 3 & 4 & 1 & 10 \\
\hline & & Female & 2 & 4 & 2 & 2 & 10 \\
\hline & & Total & 8 & 14 & 12 & 6 & 40 \\
\hline
\end{tabular}


Table 2 Comparison of Fine Motor Skill in Children with or without Down Syndrome

\begin{tabular}{lcccc}
\hline & \multicolumn{2}{c}{ Fine Motor Skill } & \\
\cline { 3 - 4 } & & Low & High & p-value \\
& Scores $=0-50$ & Scores $=50-100$ & \\
\hline Children Group & Down syndrome & 18 & 2 & $0.0000^{*}$ \\
& Normal & 1 & 19 & \\
\hline
\end{tabular}

Note: *Chi-squared test

this study had been approved by the Health Research Ethics Committee of the Faculty of Medicine Universitas Padjadjaran No. 587/ UN6.C1.3.2/KEPK/PN/2015.

\section{Results}

From 40 children, numbers of boy and girl in each group were equal $(n=10)$. Most of the children were 10 years old (35\%), followed by 11 years $(30 \%), 9$ years $(20 \%)$ and 12 years (15\%), respectively (Table 1).

In normal children group, there were more children with high-grade fine motor skill (19 of 20 children) than low-grade fine motor skill ( 1 of 20 children). In the other hand, in Down syndrome group, there were more children with low-grade fine motor skill (18 of 20 children) than high-grade fine motor skill (2 of 20 children). The fine motor skill difference between the children with Down syndrome and normal children was highly significant $(p=0.000)$. There was also a significant difference in the ratio of low-grade fine motor skill cases to high-grade fine motor skill cases in the two groups. In the Down syndrome group, the ratio was 9:1 while in the normal group, it was 1:19.

Among the children with Down syndrome, there were 2 subjects (aged 11 and 12) who showed high-grade fine motor skill. In the normal children group, there was only 1 subject (aged 9) with low-grade fine motor skill.

\section{Discussions}

This study revealed a highly significant fine motor skill difference between the two groups. Children with Down syndrome had a lower fine motor skill compared to normal children. This study has a similar result compared to a study by Ferreira-Vasques and Lamônica ${ }^{9}$ using Denver II Test. Moreover, Santos et al. ${ }^{4}$ mentioned that speech and fine motor coordination are the two worst affected aspects in children with Down syndrome. One limitation of this study was that several children with Down syndrome have a very limited speech capability. In addition, FerreiraVasques and Lamônica $^{9}$ discovered that children with Down syndrome have difficulty in forming a complete sentence,

Table 3 Fine Motor Skill based on the Children's Age

\begin{tabular}{|c|c|c|c|c|}
\hline & & \multirow{3}{*}{$\begin{array}{c}\text { Age } \\
\text { (years) }\end{array}$} & \multicolumn{2}{|c|}{ Fine Motor Skill } \\
\hline & & & Low & High \\
\hline & & & Scores $=0-50$ & Scores $=50-100$ \\
\hline \multirow{8}{*}{ Children Groups } & Down syndrome & 9 & 4 & 0 \\
\hline & \multirow{7}{*}{ Normal } & 10 & 7 & 0 \\
\hline & & 11 & 5 & 1 \\
\hline & & 12 & 2 & 1 \\
\hline & & 9 & 1 & 3 \\
\hline & & 10 & 0 & 7 \\
\hline & & 11 & 0 & 6 \\
\hline & & 12 & 0 & 3 \\
\hline
\end{tabular}


this study had been approved by the Health Research Ethics Committee of the Faculty of Medicine Universitas Padjadjaran No. 587/ UN6.C1.3.2/KEPK/PN/2015.

\section{Results}

From 40 children, numbers of boy and girl in each group were equal $(n=10)$. Most of the children were 10 years old (35\%), followed by 11 years (30\%), 9 years $(20 \%)$ and 12 years $(15 \%)$, respectively (Table 1$)$.

In normal children group, there were more children with high-grade fine motor skill (19 of 20 children) than low-grade fine motor skill ( 1 of 20 children). In the other hand, in Down syndrome group, there were more children with low-grade fine motor skill (18 of 20 children) than high-grade fine motor skill (2 of 20 children). The fine motor skill difference between the children with Down syndrome and normal children was highly significant $(p=0.000)$. There was also a significant difference in the ratio of low-grade fine motor skill cases to high-grade fine motor skill cases in the two groups. In the Down syndrome group, the ratio was 9:1 while in the normal group, it was 1:19.

Among the children with Down syndrome, there were 2 subjects (aged 11 and 12) who showed high-grade fine motor skill. In the normal children group, there was only 1 subject (aged 9) with low-grade fine motor skill.

\section{Discussions}

This study revealed a highly significant fine motor skill difference between the two groups. Children with Down syndrome had a lower fine motor skill compared to normal children. This study has a similar result compared to a study by Ferreira-Vasques and Lamônica ${ }^{9}$ using Denver II Test. Moreover, Santos et al. ${ }^{4}$ mentioned that speech and fine motor coordination are the two worst affected aspects in children with Down syndrome. One limitation of this study was that several children with Down syndrome have a very limited speech capability. In addition, Ferreira-Vasques and Lamônica9 discovered that children with Down syndrome have difficulty in forming a complete sentence, or even a word, and expressing their thoughts. In practice sessions, such children tended not to ask questions even when they did not understand something. This might be because these children realized that the operator would probably not understand what they were trying to communicate. As such, it would be preferred if their teachers or parents accompany them throughout data collection so as to facilitate easier communication.

Fine motor skill got better as the children got older (Table 3). In the Down syndrome group, the only 2 children with high-grade fine motor skill were 11 and 12 years old. Compared to other children in the same group, the 2 children had a better speech skill and a faster grasp of how to play Nintendo Wii. Meanwhile, the only normal child with lowgrade fine motor skill was 9 years old. By observation, that particular child had a low enthusiasm in playing Nintendo Wii. The child also confessed to never playing any video game console before and did not have any interest in such games. The child might have a fine motor skill disorder or a lower cognitive skill when compared to other normal children, a condition that surely demands further investigations. Comparison between members with the same age of two groups revealed that children with Down syndrome had a delay on achieving the level of fine motor skill shown in their corresponding age. The youngest child with Down syndrome who had a highgrade fine motor skill was 11 years old. This delay is consistent with the study by Frank and Esbensen..$^{10}$ The developmental delay in children with Down syndrome was not only found in fine motor skill but also in cognitive aspect. ${ }^{1}$ In cognitive developmental delay, the severity varies from mild (IQ 50-70), moderate (IQ 35-50), to severe (IQ 20-35).3 Bruni $^{3}$ stated that the cognitive levels of a child affects his motor skill development and vice versa. Consequently, a child with a low cognitive capability has a high probability of having delayed motor development. ${ }^{3}$ The statement corresponding with this study findings that established the cognitive level was linearly correlated with the fine motor skill in both groups of children. The unavailable information on cognitive capabilities was one of the limitations of this study, since only few parents knew what their children's IQs were. Interviews revealed that some parents had already forgotten it while some children had never been tested before. Further analysis on the relationship between the cognitive levels and delayed fine motor development, especially in children with Down syndrome, was therefore not performed.

In this study, fine motor skill was measured via in-game scores in a Nintendo Wii game. Other than being used as a therapy modality, Nintendo Wii can also be used to measure 
motor skill levels, as retrieved from informative feedback. ${ }^{7}$ Informative feedback from this type of therapy gave information on the patient's performance in fulfilling exercises in the form of in-game scores. ${ }^{7}$ The score information displayed on screen represented the player's ability in finishing the game. ${ }^{7}$ Even though the game Cooking Mama $\mathbb{C}$ has more appeals to the girls, there was no observable difference of the general level of enthusiasm between the boys and the girls when playing the game.

Several children from the control group admitted to frequently playing other video game consoles, such as the Playstation $®$. Such children achieved higher scores compared to children who had never or infrequently played the Playstation $®$. The finding led to one limitation of this study, i.e. different baseline of the two groups. No children in the study group (children with Down syndrome group) had ever played a video game while some subjects in the control group (normal children) had played video games before.

Based on the presented discussion above, the limitations of this study were the unavailable information on speech skill, cognitive skill, and history of exposure to virtual reality or video game consoles, which might have a close relationship and a significant influence on the measurement procedure in this study. Meanwhile, interviews with caretakers of children with Down syndrome revealed that some children did not complete their therapies. The mentioned reasons were the high cost of therapy, the high frequency and long period of therapy, lack of caretakers that can accompany the children throughout therapy sessions, and the children's refusal to go to therapy sessions. The short period of the study was also one of the limitations of this study. Data collection from children with Down syndrome required much more time compared to normal children. A child with Down syndrome needed, in average, 45 minutes to finish data collection.

In conclusion, there is a significant difference in fine motor skill between the two groups, where the fine motor skill of children with Down syndrome is lower than normal children. With increasing age, the fine motor skill of children was also increasing.

Nintendo Wii, an established physical therapy modality, can also be used to measure fine motor skill. However, in fine motor skill measurement using Nintendo Wii, consideration should also be given to the subject's speech skill, cognitive skill, and history of playing virtual reality games or video game consoles.

\section{References}

1. van Gameren-Oosterom HB, Fekkes $M$, Buitendijk SE, Mohangoo AD, Bruil J, Van Wouwe JP. Development, problem behavior, and quality of life in a population based sample of eight-year-old children with Down syndrome. PLoS One. 2011;6(7):18.

2. Bull MJ. Clinical report-Health supervision for children with down syndrome. Pediatrics. 2011;128(2):393-406.

3. Bruni M. Fine motor skills in children with down syndrome: a guide for parents and professionals topics in down syndrome. 2nd ed. Bethesda: Woodbine House; 2006.

4. Santos APM, Weiss SLI, Almeida GMF. Assessment and intervention in the motor development of a child with down syndrome. Rev Bras Educ Espec. 2010;16(1):19-30.

5. Samia A, Rahman A, Rahman. Efficacy of Virtual Reality-Based Therapy on Balance in Children with Down Syndrome. J Appl Oral Sci. 2010;10(2):254-61.

6. Ortiz-Catalan M, Nijenhuis S, Ambrosch $\mathrm{K}$, Bovend'Eerdt T, Koenig S, Lange B. Virtual reality. In: Pons JL, Toricelli D, editors. Emerging therapies in neurorehabilitation. 1st ed. Heidelberg: Springer-Verlag; 2013. p. 249-65.

7. Berg P, Becker T, Martian A, Primrose KD, Wingen J. Motor control outcomes following Nintendo Wii use by a child with down syndrome. Pediatr Phys Ther. 2012;24(1):78-84.

8. Hammond J, Jones V, Hill EL, Green D, Males I. An investigation of the impact of regular use of the Wii Fit to improve motor and psychosocial outcomes in children with movement difficulties: a pilot study. Child Care Health Dev. 2014;40(2):165-75.

9. Ferreira-Vasques AT, Lamônica DA. Motor, linguistic, personal and social aspects of children with Down syndrome. J Appl Oral Sci. 2015;23(4):424-30.

10. Frank K, Esbensen AJ. Fine motor and self-care milestones for individuals with Down syndrome using a Retrospective Chart Review. J Intellect Disabil Res. 2015;59(8):719-29. 